\title{
MANAJEMEN MUTU SEKOLAH DASAR
}

\author{
Oleh: \\ Moh. Nahrowi \\ IAI Al-Falah As-sunniyyah Kencong \\ Moh.nahrowi@gmail.com
}

\begin{abstract}
Elementary school as a basic education institution, is a place for educational processes for children aged 7 - 12 years, has a complex and dynamic system and has a very unique characteristics. In its activities, schools are places that are not just a gathering place for teachers and students, but are in a complex and interrelated system of order, therefore elementary schools are seen as an educational organization that requires very intensive management in order to realize quality within these institutions. Moreover, the core activities of elementary school organizations are managing human resources (HR) that are expected to produce quality graduates, have complete basic knowledge at the cognitive, affective and psychomotor level as a provision to continue to a higher education level. Based on the facts mentioned above, of course efforts need to be improved, one of which is to reorient the implementation of education through school quality management. A management approach that focuses on improving the quality of education through improving quality with the concept of Quality Assurance, Quality Assurance, Change of culture, Upside down organization and Keeping close to the customer. Aspects that become high bargaining power which are considered as a measure of quality for the community include Learner quality management, Quality Management of Education and Education Personnel, Curriculum and Learning quality management, Financial quality management, Infrastructure quality management, Public Relations quality management, Quality management Special services
\end{abstract}

Keyword: School, Quality Management.

\section{ABSTRAK}

Sekolah Dasar sebagai intitusi pendidikan dasar, merupakan wadah tempat proses pendidikan untuk anak usia 7 - 12 tahun, memiliki sistem yang kompleks dan dinamis serta memiliki kekhasan yang sangat unik. Dalam kegiatannya, sekolah adalah tempat yang bukan hanya sekedar tempat berkumpul guru dan murid, melainkan berada dalam satu tatanan sistem yang komplek dan saling berkaitan, oleh karena itu sekolah dasar dipandang sebagai suatu organisasi pendidikan yang membutuhkan pengelolaan yang sangan intensif guna mewujudkan mutu dalam institusi tersebut. Lebih dari itu, kegiatan inti organisasi sekolah dasar adalah mengelola sumber daya manusia (SDM) yang diharapkan menghasilkan lulusan yang berkualitas, memiliki pengetahuan dasar yang utuh pada tataran kognitif, afektif dan psikomotorik sebagai bekal untuk melanjutkan ke jenjang pendidiakan yang lebih tinggi. Berdasarkan kenyataan-kenyataan tersebut di atas, tentu saja perlu dilakukan upaya-upaya perbaikan, salah satunya adalah melakukan reorientasi penyelenggaraan pendidikan yaitu melalui manajemen mutu sekolah. Pendekatan manajemen yang memusatkan perhatian pada peningkatan mutu pendidikan melalui peningkatan mutu dengan konsep Quality Assurance, Quality Assurance, 
Change of culture, Upside down organizatian dan Keeping close to the customer. Aspek-aspek yang menjadi daya tawar tinggi yang dianggap sebagai ukuran mutu bagi masyarakat meliputi Manajemen mutu Peserta Didik, Manajemen mutu Tenaga Pendidikan dan Kependidikan, Manajemen mutu Kurikulum dan Pembelajaran, Manajemen mutu Keuangan, Manajemen mutu Sarana Prasarana, Manajemen mutu Hubungan Masyarakat, Manajemen mutu layanan Khusus

Keyword : Sekolah, Manajemen mutu.

\section{PENDAHULUAN}

Salah satu permasalahan pendidikan yang dihadapi oleh bangsa Indonesia adalah rendahnya mutu pendidikan pada setiap jenjang dan satuan pendidikan, khususnya pendidikan dasar. Berbagai usaha telah dilakukan untuk meningkatkan mutu pendidikan nasional, misalnya pengembangan kurikulum nasional dan lokal, peningkatan kompetensi guru melalui pelatihan, pengadaan buku dan alat pelajaran, pengadaan dan perbaikan sarana dan prasarana pendidikan dan peningkatan mutu manajemen sekolah. Namun demikian, berbagai indikator mutu pendidikan belum menunjukkan peningkatan yang berarti. Sebagian sekolah, terutama di kotakota, menunjukkan peningkatan mutu pendidikan yang cukup menggembirakan, namun sebagaian lainnya masih memprihatinkan.

Dalam Al-Qur'an dijelaskan dalam surat An-Nisa' ayat 9.

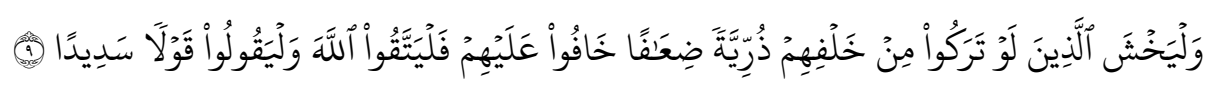

Artinya" Dan hendaklah takut kepada Allah orang-orang yang seandainya meninggalkan dibelakang mereka anak-anak yang lemah, yang mereka khawatir terhadap (kesejahteraan) mereka. Oleh sebab itu hendaklah mereka bertakwa kepada Allah dan hendaklah mereka mengucapkan perkataan yang benar (Q.S. An-Nisa: 9)

Dari ayat di atas tentunya ada amanat besar yang bisa kita perjuangkan yakni untuk tidak meninggalkan generasi muda dengan keadaan yang lemah baik secara material maupun keilmuan. Memperjuangkan dalam konteks sekolah dasar adalah mempersiapakan manajemen lembaga pendidikan yang baik supaya output dari sekolah dasar memiliki kemampuan akademik dan non-akademik yang memuaskan.

Sekolah Dasar sebagai intitusi pendidikan dasar, merupakan wadah tempat proses pendidikan untuk anak usia 7 - 12 tahun, memiliki sistem yang kompleks dan dinamis serta memiliki kekhasan yang sangat unik. Dalam kegiatannya, sekolah adalah tempat yang bukan 
hanya sekedar tempat berkumpul guru dan murid, melainkan berada dalam satu tatanan sistem yang komplek dan saling berkaitan, oleh karena itu sekolah dasar dipandang sebagai suatu organisasi pendidikan yang membutuhkan pengelolaan yang sangan intensif guna mewujudkan mutu dalam institusi tersebut. Lebih dari itu, kegiatan inti organisasi sekolah dasar adalah mengelola sumber daya manusia (SDM) yang diharapkan menghasilkan lulusan yang berkualitas, memiliki pengetahuan dasar yang utuh pada tataran kognitif, afektif dan psikomotorik sebagai bekal untuk melanjutkan ke jenjang pendidiakan yang lebih tinggi.

Sekolah dasar dipandang sebagai suatu organisasi yang didesain untuk dapat berkontribusi terhadap upaya peningkatan kompetensi untuk anak-anak dan mengarahkankan pada minat dan bakat peserta didik melalui identifikasi sedini mungkin sehingga mampu memberikan stimulus kepada orang tua untuk selalu mengawasi anak-anaknya kapanpun dan dimanapun.

Faktor-faktor yang menyebabkan mutu pendidikan sekolah dasar tidak mengalami peningkatan secara merata ${ }^{1}$. Faktor pertama, kebijakan dan penyelenggaraan pendidikan nasional menggunakan pendekatan educational production function atau input-output analysis yang tidak dilaksanakan secara konsekuen. Pendekatan ini melihat bahwa lembaga pendidikan berfungsi sebagai pusat produksi yang apabila dipenuhi semua input (masukan) yang diperlukan dalam kegiatan produksi tersebut, maka lembaga ini akan menghasilkan output yang dikehendaki.

Faktor kedua, penyelenggaran pendidikan nasional diselenggarakan secara birokratiksentralistik sehingga menempatkan sekolah sebagai penyelenggara pendidikan sangat tergantung pada keputusan birokrasi yang mempunyai jalur yang sangat panjang dan kadangkadang kebijakan yang dikeluarkan tidak sesuai dengan kondisi sekolah setempat.

Faktor ketiga, peran serta warga sekolah khususnya guru dan peran serta masyarakat khususnya orang tua siswa dalam penyelenggaraan pendidikan selama ini sangat minim. Partisipasi guru dalam pengambilan keputusan sering diabaikan, padahal terjadi atau tidaknya perubahan di sekolah sangat tergantung pada guru.

Berdasarkan kenyataan-kenyataan tersebut di atas, tentu saja perlu dilakukan upayaupaya perbaikan, salah satunya adalah melakukan reorientasi penyelenggaraan pendidikan yaitu melalui manajemen mutu sekolah.

\footnotetext{
${ }^{1}$ Soebahar, Pendidikan Islam dan Trend Masa Depan (Jember: Pena salsabila, 2011), 68. 124 | Jurnal Auladuna
} 


\section{KAJIAN TEORI}

\section{A. Pengertian Manajemen Mutu Sekolah Dasar}

Secara etimologi manajemen berasal dari bahasa Inggris "management" yang dikembangkan dari kata "to manage" yang berarti mengatur atau mengelola ${ }^{2}$.menurut Terry manajemen adalah suatu proses yang melibatkan pengarahan suatu kelompok orang ke arah tujuan organisasi yang nyata ${ }^{3}$. Follet mengatakan manajemen adalah kiat ${ }^{4}$. Mutu berarti agenda utama ${ }^{5}$. Syarbini berpendapat mutu adalah ukuran baik buruk suatu benda, kadar, taraf berupa kepandaian, kecerdasan, kecakapan dan sebagainya ${ }^{6}$.Sekolah Dasar dalam Undang-Undang RI. Nomor 20 tahun 2003 tentang Sistem Pendidikan Nasional Pasal 14 menejelaskan Jenjang pendidikan dasar bagian dari tahapan dalam pendidikan formal.

Berdasarkan pengertian di atas maka Manajemen Mutu Sekolah Dasar merupakan proses mengelola kinerja berupa perencanaan, pengorganisasian, pelakasanan, monitoring dan evaluasi dalam menyelenggarakan pendidikan yang bermutu pada sekolah dasar. Mutu dalam pandangan invidu satu dengan lainnya memiliki standarisasi yang berbeda, masyarakatakan hanya bisa menilai mutu dari sekolah dasar pada saat sekolah dasar tersebut dibandingkan dengan sekolah dasar lainnya, maka akan nampak mutu dari lembaga/ sekolah dasar yang sedang dibandingkan.

\section{B. Tujuan dan manfaat Manajemen Mutu Sekolah}

Manajemen Mutu Sekolah Dasar bertujuan untuk memandirikan atau memberdayakan sekolah dasar melalui pemberian kewenangan (otonomi) kepada sekolah, pemberian fleksibilitas yang lebih besar kepada sekolah untuk mengelola sumberdaya sekolah, dan mendorong partisipasi warga sekolah dan masyarakat untuk meningkatkan mutu pendidikan. Lebih rincinya Manajemen Peningkatan Mutu Berbasis Sekolah memiliki tujuan untuk ${ }^{7}$ :

\footnotetext{
${ }^{2}$ Samsudin, Manajemen Sumber Daya Manusia ( Bandung: Rosdakarya, 2010), 15.

${ }^{3}$ Terry, Dasar-Dasar Manajemen (Jakarta: Bumi aksara, 2014), v.

${ }^{4}$ Nanang Fattah, Landasan Manajemen Pendidikan (Bandung: Rosdakarya, 2005), 1.

${ }^{5}$ Edward Salis, Manajemen Mutu Pendidikan (Yogyakarta: IRCISoD, 2012), 29.

${ }^{6}$ Syarbini, Manajemen Madrasah (Bandung: Alfabeta, 2013), 95.

${ }^{7}$ Syarbini, Manajemen Madrasah (Bandung: Alfabeta, 2013), 99.

Vol. 미. №. 기. April 2019
} 
1. Meningkatkan Mutu Pendidikan sekolah dasar melalui kemandirian dan inisiatif sekolah dalam mengelola dan memberdayakan sumber daya yang tersedia.

2. Meningkatkan kepedulian warga sekolah dan masyarakat dalam penyelenggaraan pendidikan melalui pengambilan keputusan bersama.

3. Meningkatkan tanggung jawab sekolah kepada orang tua, masyarakat, dan pemerintah tentang mutu sekolah.

4. Meningkatkan kompetensi yang sehat antar sekolah untuk pencapaian mutu pendidikan yang diharapkan.

5. Memperdayakan potensi sekolah yang ada agar menghasilkan lulusan yang berhasil guna dan berdaya guna.

\section{Prinsip Mutu Pendidikan}

Deming sebagaimana dikutip oleh Nasution mengungkapkan beberapa prinsip mutu sebagai berikut ${ }^{8}$ :

1. Menciptakan konsistensi tujuan untuk memperbaiki produk agar bersaing.

2. Mengadopsi filosofi baru.

3. Menghentikan ketergantungan pada adanya inspeksi dan digantikan dengan upaya pencapaian mutu.

4. Menghentikan anggapan bahwa penghargaan dalam bisnis terletak pada harga

5. Tingkatkan terus sistem produksi dan jasa agar kualitas dan produktivitas semakin meningkat.

6. Terapkan on the job training.

7. Tenaga kerja dan teknologi bisa berjalan dengan baik.

8. Hilangkan rasa takut agar setiap orang agarsetiap orang bisa bekerja dengan efektif.

9. Bekerjasama dalam tim.

10. Pemantapan metode yang dapat meingkatkan mutu.

11. Hialngkan kuota.

12. Hilangkan penghambat.

\section{Strategi pelaksanaan Manajemen Mutu Sekolah Dasar}

\footnotetext{
${ }^{8}$ Syarbini, ..., 97.

126 | Jurnal Auladuna
} 
Strategi adalah langkah-langkah sistematis dan sistemik dalam melaksanakan rencana secara menyeluruh (makro) dan berjangka panjang dalam pencapaian tujuan model Manajemen Mutu Sekolah. Perlu disadari bahwa reformasi manajemen pendidikan persekolahan dengan menggunakan model Manajemen Mutu Sekolah merupakan tuntutan yang mendesak. Namun demikian, tuntutan Manajemen Mutu Sekolah bukanlah satusatunya model yang dapat mendongkrak mutu pendidikan tanpa dukungan faktor lain. Ada sejumlah faktor lain yang mendukung dan menentukan diantaranya tingkat prestasi stakeholder dan kondisi sosial ekonomi masyarakat. Artinya sekolah tidak dapat berjalan sendiri dalam upaya meningkatkan mutu efisiensi, pemerataan pendidikan dan kemandirian sekolah. Kondisi politik atau kebijakan pemerintah dalam hal manajemen/organisasi/kepemimpinan, proses belajar mengajar, sumber daya manusia dan administrasi sekolah merupakan sejumlah komponen Manajemen Mutu Sekolah yang diperlukan dalam konteks persekolahan di Indonesia.

Penerapan disesuaikan dengan pemberlakuan Manajemen Mutu Sekolah dibagi dalam tiga tingkatan Manajemen Mutu Sekolah secara penuh (tinggi), Manajemen Mutu Sekolah tingkat menengah (sedang), sekolah dan Manajemen Mutu Sekolah secara minimal (rendah). Dalam menentukan tingkatan sekolah dan Manajemen Mutu Sekolah ada lima persyaratan yang perlu dipenuhi yaitu :

1. Pemilihan Kepala sekolah dan guru

2. Pembentukan partisipasi masyarakat

3. Lokasi/kemampuan dasar orang tua

4. Kemampuan pengadaan dana

5. Nilai Ebtanas Murni

Kelima kriteria tersebut dihubungkan dengan tipe sekolah (penuh, menengah dan minimal).

\section{E. Faktor pendukung keberhasilan Manajemen Mutu Sekolah Dasar}

Implementasi Manajemen Mutu Sekolah akan sangat dipengaruhi oleh beberapa faktor yang sifatnya internal di lingkungan sekolah ataupun faktor eksternal di luar sekolah. Secara umum beberapa faktor pendukung Manajemen Mutu Sekolah adalah sebagai berikut :

1. Kepemimpinan dan Manajemen Sekolah yang professional

Vol. I. №. DI. April 2019

Jurnal Auladuna | 127 
Manajemen Mutu Sekolah akan berhasil jika ditopang oleh kemampuan professional kepala sekolah dalam memimpin dan mengelola sekolah secara efektif dan efisien, serta mampu menciptakan iklim organisasi di sekolah yang kondusif untuk proses belajar mengajar'.

2. Kondisi sosial, ekonomi, dan apresiasi masyarakat terhadap pendidikan

Faktor eksternal akan turut menentukan keberhasilan Manajemen Mutu Sekolah adalah kondisi tingkat pendidikan orang tua siswa dan masyarakat ${ }^{10}$. Kemampuan dalam membiayai pendidikan, serta tingkat apresiasi dalam mendorong anak untuk terus belajar.

3. Dukungan pemerintah

Faktor ini sangat menentukan efektivitas dan implementasi Manajemen Mutu Sekolah terutama bagi sekolah yang kemampuan orang tua/masyarakatnya relatif belum siap memberikan kontribusi terhadap penyelenggaraan pendidikan. Alokasi dana pemerintah (APBN/APBD) sekurang-kurangnya 20\% dan pemberian kewenangan dalam pengelolaan sekolah kepada sekolah menjadi penentu keberhasilan ${ }^{11}$.

4. Profesionalisme

Faktor ini sangat strategis menentukan mutu dan kinerja sekolah. Tanpa profesionalisme kepala sekolah, guru, pengawas, dan tenaga kependidikan yang lain akan sulit dicapai PBM yang bermutu serta prestasi siswa.

\section{F. Total Quality Management (TQM)}

TQM (Total Quality Manajemen) atau Manajemen Mutu Terpadu (MMT) di bidang pendidikan merupakan konsep baru dalam rangka meningkatkan mutu total bertujuan untuk memandirikan atau memberdayakan sekolah yang berorientasi kepada kebutuhan pengguna (customers) siswa dan masyarakat ${ }^{12}$.

Total Quality Management (TQM) adalah suatu pendekatan manajemen yang memusatkan perhatian pada peningkatan mutu pendidikan melalui peningkatan mutu komponen terkait. Kunci pokok keberhasilan atau kegagalan implementasi TQM adalah

\footnotetext{
${ }^{9}$ Rodliyah, Supervisi Pendidikan dan Pembelajaran (Jember: STAIN Jember Press, 2014), 47.

${ }^{10}$ Syarbini, Manajemen Madrasah (Alfabeta: 2013), 91.

${ }^{11}$ Pidarta, Landasan Pendidikan (Jakarta: Renika Cipta, 2009), 44.

${ }^{12}$ Edward Salis, Manajemen Mutu Pendidikan (Yogyakarta: IRCISoD, 2012), 6.

128 | Jurnal Auladuna
} 
manajemen komitmen ${ }^{13}$. Apabila manajemen mempunyai dan memegang teguh komitmennya, kemungkinan besar mereka akan berhasil. Sebaliknya, apabila mereka kurang komitmen bisa dipastikan bahwa organisasi akan mengalami kegagalan mencapai TQM. Komitmen terhadap waktu ini berupa kesadaran manajemen bahwa implementasi TQM, tergantung pada kondisi sekolah, memerlukan pengorbanan waktu. Dalam hal ini manajemen harus menyediakan waktu yang cukup berkonsentrasi pada TQM.

Komponen yang terkait dengan TQM Pendidikan ${ }^{14}$ :

\section{Continous Improvement}

Continous Improvement adalah Perbaikan secara terus menerus, konsep ini mengandung pengertian bahwa pihak pengelolo senantiasa melakukan berbagai perbaikan dan peningkatan mutu secara terus menerus terhadap program dan kinerja pada semua komponen yang terlibat dalam penyelenggaraan pendidikan. Perbaikan menuju kesempurnaan merupakan hasil dari monitoring dan evaluasi yang dilakukan oleh lembaga secara bertahap dan terencana ${ }^{15}$.

\section{Quality Assurance}

Quality Assurance adalah Menentukan standar mutu, konsep ini berada pada tahapan perencanaan (planning) dalam fungsi manajemen. Beberapa program yang ingin dicapai didesain berpedoman pada mutu. Aplikasi dari konsep ini berada pada Rencana Kerja Tahunan Sekolah (RKTS) dan rencana kerja sekolah (RKS) ${ }^{16}$.

3. Change of culture

Change of culture adalah Perubahan kultur, yang dimaksud dalam konsep ini adalah merubah budaya organisasi yang menghargai mutu dan menjadikan mutu sebagai orientasi semua komponen organisasional. Jika menejemen ini ditetapkan di instansi pendidikan, maka pihak pimpinan harus berusaha membangun kesadaran para anggotanya, mulai dari pemimpin sendiri, staf, guru, pelajar dan semua yang terlibat dalam penyelenggaraan pendidikan untuk sadar akan mutu dalam pendidikan.

\section{Upside down organizatian}

Upside down organizatian adalah Perubahab organisasi, jika visi misi serta tujuan organisasi sudah berubah atau mengalami perkembangan, maka sangat dimungkinkan

\footnotetext{
${ }^{13}$ Edward Salis, ..., 12

${ }^{14}$ Edward Salis, ..., 7-13.

${ }_{15}^{15}$ Maryono, Supervisi Pendidikan( Jogjakarta: Ar-ruzz, 2011), 20.

${ }^{16}$ Lihat juga Ahmadi, Manajemen Pendidikan Islam (Yogyakarta:LaksBang, 2012), 39-46.
}

Vol. ㅁ‥ №. ㄱ. April 2019 
terjadinya perubahan organisasi, perubahan yang dimasksud adalah perubahan terhadap sistem kinerja dalam penyelenggaraan pendidikan yang meliputi perubahan wewenang, tanggungjawab dan tugas-tugas bagi setiap unsur bagian.

\section{Keeping close to the customer}

Keeping close to the customer adalah Mempertahankan hubungan dengan pelanggan, kepuasan pelanggan menjadi merupakan target yang ingin dicapai, maka perlu mempertahankan hubungan dengan baik kepada seluruh pelanggan dalam pendidikan dan inilah yang dikembangkan oleh unit public relations.

Penyebab kegagalan intern dalam TQM yaitu masalah sumber daya manusia (SDM). Kelemahan yang lazimnya berupa tidak memadainya kualitas SDM yang tersedia untuk mencapai tingkat kualitas tertentu. Hal ini mungkin saja ditimbulkan karena proses rekrutmen yang kurang baik atau manajemen yang hanya mementingkan biaya pegawai yang murah.

Penyebab kegagalan intern lainnya yaitu faktor cost. Manajemen mengabaikan perhitungan aspek pembiayaan, sehingga pembiayaan TQM melebihi hasil yang bisa diraih. Salah satu implementasi TQM adalah untuk memperbaiki pula posisi keuangan (finance performance).

\section{G. Ruang Lingkup Manajemen Mutu Sekolah Dasar}

Mewujudkan mutu di Sekolah dasar memiliki tantangan tersendiri bagi semua orang yang terlibat di dalamnya. Seluruh SDM yang bertanggung jawab dalam pengelolaan sekolah dasar perlu mengetahui sektor-sektor yang menjadi titik poin untuk menunjolkan mutu pada setiap lembagapendidikan termasuk sekolah dasar. Dibawah ini akan dipaparkan aspekaspek yang menjadi daya tawar tinggi yang dianggap ukuran mutu bagi masyarakat pendapat mulyasa yang dikutib oleh Syarbini ${ }^{17}$ :

1. Manajemen mutu Peserta Didik

Manajemen mutu Peserta Didik ini berisi penataan terhadap kegiatan yang berkaitan dengan peserta didik mulai dari masuk dan sampai pada keluarnya dari sekolah. Misalnya PPDB dan pola rekruitmen peserta didik baru. Manajemen peserta didik ini bertujuan untuk mengatur berbagai kagiatan dalam bidang kesiswaan baik inkurikuler

\footnotetext{
${ }^{17}$ Syarbini, Manajemen Madrasah (Alfabeta: 2013), 13.
} 130 | Jurnal Auladuna 
maupun ekstrakurikuler agara kegiatan pembelajaran disekolah dapat berjalan dengan lancar, tertib dan teratur, serta mencapai tujuan pendidikan sekolah.

2. Manajemen mutu Tenaga Pendidikan dan Kependidikan

Yang termasuk dalam tenaga pendidik adalah semua guru di lembaga tersebut dan yang termasuk tenaga kependidikan adalah staf karyawan dilembaga tersebut. Pengaturan menuju pada mutu meliputi perencanaan pegawai, pengadaan pegawai, pembinaan dan pengembangan pegawai, promisi, pemberhentian pegawai, kompensasi pegawai dan penilaian kinerja pegawai ${ }^{18}$.

3. Manajemen mutu Kurikulum dan Pembelajaran

Menejemen mutu kurikulum dan pembelajaran mencakup kegiatan perencanaan, pelaksanaan dan penilaian kurikulum. Untuk menjamin efektifitas perkembangan kurikulum dan program pengajaran kepala sekolah bersama dengan jajarannya harus mampu menjabarkan isi kurikulum secara lebih rinci dan dituangkan kedalam program tahunan, semester dan bulanan yang kemudian wajib dikembangkan oleh guru.

4. Manajemen mutu Keuangan

Komponen utama manajemen keuangan adalah prosedur anggaran, prosedur akuntansi keuangan, pembelajaran, perundangan dan prosedur pendistribusian, prosedur investasi dan prosedur pemeriksaan.

5. Manajemen mutu Sarana Prasarana

Manajemen mutu sarana dan prasarana berupa kegiatan perencanaan, pengadaan, pengawasan, perawatan, penyimpanan, inventaris dan penghapusan serta penataan.

6. Manajemen mutu Hubungan Masyarakat

Manajemen mutu hubungan masyarakat bertujuan untuk memajukan kualitas pembelajaran, memperkokoh tujuan serta meningkatkan kualitas hidup dan pemberdayaan masyarakat serta meningkatkan motivasi masyarakat untuk menjalin hubungan dengan sekolah.

7. Manajemen mutu layanan Khusus

Manajemen mutu layanan khusus meliputi layanan perpustakaan, kesehatan UKS, dan keamanan sekolah serta bimbingan konseling.

${ }^{18}$ Lihat juga Samsudin, Manajemen Sumber Daya Manusia ( Bandung: Rosdakarya, 2010), 33. Vol. 미. №. ㄱ. April 2019 


\section{KESIMPULAN}

Berbagai kenyataan tidak optimalnya mutu sekolah dasar dipengaruhi banyak faktor, salah satunya adalah manajemen pendidikan. Dalam kenyataan, manajemen pendidikan sekolah yang selama ini sentralistik telah menempatkan sekolah pada posisi marginal, kurang berdaya, kurang mandiri, dan bahkan terpasung kreativitasnya.

Sekolah dipandang sebagai suatu organisasi yang didesain untuk dapat berkontribusi terhadap upaya peningkatan kualitas hidup bagi masyarakat suatu bangsa. Sebagai salah satu upaya peningkatan kualitas sumber daya manusia serta peningkatan derajat sosial masyarakat bangsa, sekolah dasar sebagai intitusi pendidilan pertama perlu dikelola, dimenej, diatur, ditata dan diperdayakan, agar sekolah dasar dapat menghasilkan out put yang berkualitas.

Penerapan disesuaikan dengan pemberlakuan Manajemen Mutu Sekolah dibagi dalam tiga tingkatan Manajemen Mutu Sekolah secara penuh (tinggi), Manajemen Mutu Sekolah tingkat menengah (sedang), sekolah dan Manajemen Mutu Sekolah secara minimal (rendah). Konsep Manajemen Mutu Sekolah ini merupakan ide baru dalam wacana manajemen pendidikan di Indonesia. Sebagai ide baru tentu saja konsep ini tidak otomatis sempurna.

TQM (Total Quality Manajemen) atau Manajemen Mutu Terpadu (MMT) dibidang pendidikan merupakan konsep baru dalam rangka meningkatkan mutu total bertujuan untuk memandirikan atau memberdayakan sekolah yang berorientasi kepada kebutuhan penggunaan (customers) siswa dan masyarakat.

Total Quality Management (TQM) adalah suatu pendekatan manajemen yang memusatkan perhatian pada peningkatan mutu pendidikan melalui peningkatan mutu dengan konsep Quality Assurance, Quality Assurance, Change of culture, Upside down organizatian dan Keeping close to the customer.

Aspek-aspek yang menjadi daya tawar tinggi yang dianggap sebagai ukuran mutu bagi masyarakat meliputi Manajemen mutu Peserta Didik, Manajemen mutu Tenaga Pendidikan dan Kependidikan, Manajemen mutu Kurikulum dan Pembelajaran, Manajemen mutu Keuangan, Manajemen mutu Sarana Prasarana, Manajemen mutu Hubungan Masyarakat, Manajemen mutu layanan Khusus

\section{DAFTAR PUSTAKA}

Ahmadi, 2012. Manajemen Pendidikan Islam, Yogyakarta:Laksbang. 132 | Jurnal Auladuna 
Fattah, Nanang, 2005. Landasan Manajemen Pendidikan, Bandung: Rosdakarya.

Maryono, 2011. Supervisi Pendidikan, Jogjakarta: Ar-ruzz.

Pidarta, Made, 2009. Landasan Pendidikan, Jakarta: Renika Cipta.

Rodliyah, St, 2014. Supervisi Pendidikan dan Pembelajaran, Jember: STAIN Jember Press.

Salis, Edward, 2012. Manajemen Mutu Pendidikan, Yogyakarta: IRCISoD.

Samsudin, 2010. Manajemen Sumber Daya Manusia, Bandung: Rosdakarya.

Sekretarian Negara RI Undang-Undang Nomor 20 tahun 2003 tentang Sitem Pendidikan Nasional

Soebahar, Abd. Halim, 2011. Pendidikan Islam dan Trend Masa Depan, Jember: Pena salsabila.

Syarbini, Amirulluh, 2013. Manajemen Madrasah , Bandung: Alfabeta.

Terry, 2014. Dasar-Dasar Manajemen, Jakarta: Bumi aksara. 